\title{
MENENTUKAN DETERMINAN SUATU MATRIKS DENGAN METODE CHIO
}

\author{
Asep Saepudin \\ (Pendidikan Matematika, Fakultas Keguruan dan Ilmu Pendidikan, Universitas PGRI Adi Buana Surabaya) \\ asep.saepudin.29051993@gmail.com
}

\begin{abstract}
Matrix theory is a branch of linear algebra that discussed in the mathematical sciences. Mathematical sciences play an important role in human life, it is necessary to solve problems that can not be solved directly. Thus, the problem can be transformed into the form of a mathematical model. One is the SPL (Linear Equation System). Various methods can be used to solve it. But for the SPL with a large variable can be solved by matrix methods, namely the inverse matrix. In the inverse matrix of the determinants involved. If the search value that ordo major determinant of the matrix $(n \times n)$, it would require an effective method. One is the method of Chio. Chio method can be applied to all square matrixas long as the element is $a_{11}$ not equal to zero $\left(a_{11} \neq 0\right)$. Chio method of calculating the determinant of the matrix by decomposing determinant will look into sub-determinant of degree two $(2 \times 2)$ using the matrix element row 1 and column 1 as pointof departure. The decomposition is performed using the following sized matrix:
\end{abstract} $\left|\begin{array}{ll}a_{11} & a_{1 n} \\ a_{n 1} & a_{n n}\end{array}\right|$, for $n=1,2,3, \ldots$

Keywords: Matrix, Matrix Determinant, Chio method.

\section{PENDAHULUAN}

Teori matriks merupakan salah satu cabang ilmu aljabar linier yang menjadi pembahasan penting dalam ilmu matematika. Sejalan dengan perkembangan ilmu pengetahuan, aplikasi matriks banyak dijumpai dalam kehidupan sehari-hari, baik dalam bidang matematika maupun ilmu terapannya. Aplikasi tersebut banyak dimanfaatkan dalam menyelesaikan masalah-masalah yang berhubungan dengan kehidupan sehari-hari, misalnya pada aplikasi perbankan yang senantiasa berhubungan dengan angka-angka, dalam dunia olahraga seperti penentuan klasemen suatu pertandingan, dalam bidang ekonomi biasa digunakan untuk menganalisa input dan output seluruh sektor ekonomi.

Perhitungan nilai determinan matriks merupakan hal yang paling sulit dimengerti dalam bidang matematika. Banyak yang tidak mengerti bagaimana cara atau metode yang digunakan untuk menghitung nilai determinan matriks. Ada beberapa cara untuk menghitung nilai determinan matriks seperti metode Sarrus, minor dan kofaktor. Metode-metode tersebut memiliki kekurangan dalam setiap perhitungan. Hampir seluruh proses dalam metode tersebut sangat rumit dan sulit dipahami. Tetapi metode Chio, lebih mudah dimengerti dan dipelajari, jika dibandingkan dengan metode Sarrus, minor dan kofaktor. Perhitungan determinan dengan metode Chio dapat diterapkan pada semua matriks persegi asalkan pada $\square 11$ tidak sama dengan nol $(\square 11 \neq 0)$. Metode Chio menghitung determinan matriks dengan cara mendekomposisi determinan yang akan dicari menjadi sub-sub determinan derajat dua $2 \times 2$ menggunakan elemen matriks baris ke-1 dan kolom ke-1 sebagai titik tolaknya. Dekomposisi tersebut dilakukan dengan menggunakan matriks berukuran $2 \times 2$ berikut:

$$
\left|\begin{array}{ll}
a_{11} & a_{1 n} \\
a_{n 1} & a_{n n}
\end{array}\right| \text {, for } n=1,2,3, \ldots
$$


Pada teori matriks terdapat permasalahan menentukan nilai determinan dari matriks. Sedangkan masalah yang sering muncul dalam mencari determinan matriks biasanya berhubungan dengan ukuran matriks yang akan dicari determinannya. Semakin besar matriksnya, semakin rumit juga perhitungannya sehingga dibutuhkan formula yang tepat untuk menentukan determinan tersebut. Dengan latar belakang diatas maka penulis merumusksn judul untuk penelitian ini yakni: "Menentukan Determinan Suatu Matriks dengan Metode Chio".

\section{METODE PENELITIAN}

Penelitian ini merupakan penelitian kualitatif deskriptif. Tahap awal penelitian ini adalah studi literatur. Studi literatur adalah mencari referensi teori yang relefan dengan kasus atau permasalahan yang ditemukan.

\section{Referensi tersebut berisikan tentang:}

1. Jenis-jenis matriks

2. Operasi pada matriks

3. Invers matriks

4. Determinan matriks

Referensi ini dapat di cari dari buku, jurnal dan situssitus di internet. Output dari studi literatur ini adalah terkoleksinya referensi yang relefan dengan perumusan masalah.

Tujuannya adalah untuk memperkuat permasalahan serta sebagai dasar teori dalam melakukan studi dan juga menjadi dasar untuk menentukan determinan suatu matriks dengan metode Chio.

\section{HASIL DAN PEMBAHASAN}

Determinan memiliki beberapa sifat, yang dapat digunakan untuk mempermudah proses hitungan, antara lain:

1. Apabila semua elemen dalam satu baris atau satu kolom $=0$, maka nilai determinannya $=0$

Contoh:

Jika $A=\left[\begin{array}{ccc}1 & -3 & 2 \\ 0 & 0 & 0 \\ 4 & 2 & -1\end{array}\right]$ $\operatorname{det} A=|A|=\left|\begin{array}{ccc}1 & -3 & 2 \\ 0 & 0 & 0 \\ 4 & 2 & -1\end{array}\right|$

$\operatorname{det} A=|A|=1.0(-1)+(-3) \cdot 0 \cdot 4+2 \cdot 0 \cdot 2-(2 \cdot 0 \cdot 4+1.0 .2+(-3) \cdot 0 .(-1))$

$\operatorname{det} A=|A|=0$

Dengan elemen pada baris ke-2 semuanya nol, maka determinannya bernilai 0 .

Jika $B=\left|\begin{array}{ccc}0 & 2 & 5 \\ 0 & -1 & 2 \\ 0 & 3 & 4\end{array}\right|$

Karena elemen pada kolom ke-1 semuanya nol, maka determinannya bernilai 0 .

2. Nilai determinan suatu matriks tidak berubah apabila semua baris diubah menjadi kolom atau semua kolom diubah manjadi baris.

Contoh:

Jika $A=\left|\begin{array}{cc}3 & 5 \\ -1 & 2\end{array}\right|$

$$
\operatorname{det} A=|A|=11
$$

Sedangkan

$$
\begin{aligned}
& A^{T}=\left|\begin{array}{cc}
3 & -1 \\
5 & 2
\end{array}\right| \\
& \operatorname{det} A^{T}=\left|A^{T}\right|=3.2-(-1) .5=11
\end{aligned}
$$

3. Pertukaran tempat antara baris dengan baris atau kolom dengan kolom pada suatu determinan akan mengubah tanda determinan.

Contoh:

Jika $A=\left|\begin{array}{ccc}3 & 5 & -1 \\ 2 & 0 & 3 \\ 1 & 7 & 4\end{array}\right|$

$\operatorname{det} A=|A|=\left|\begin{array}{ccc}3 & 5 & -1 \\ 2 & 0 & 3 \\ 1 & 7 & 4\end{array}\right|$

$\operatorname{det} A=|A|=3 \cdot 0 \cdot 4+5 \cdot 3 \cdot 1+(-1) \cdot 2 \cdot 7-((-1) \cdot 0 \cdot 1+3 \cdot 3 \cdot 7+5 \cdot 2 \cdot 4)$

$$
=-102
$$

Jika elemen-elemen pada baris ke-1 dan ke-3 ditukar letaknya, maka didapat:

$$
B=\left|\begin{array}{ccc}
1 & 7 & 4 \\
2 & 0 & 3 \\
3 & 5 & -1
\end{array}\right|
$$




$$
\begin{aligned}
\operatorname{det} B=|B| & =\left|\begin{array}{ccc}
1 & 7 & 4 \\
2 & 0 & 3 \\
3 & 5 & -1
\end{array}\right| \\
\operatorname{det} B=|B| & =1.0 \cdot(-1)+7.3 \cdot 3+4.2 \cdot 5-(4 \cdot 0.3+1.3 .5+7.2 .(-1)) \\
& =102
\end{aligned}
$$

Maka dari uraian diatas dapat dilihat: $\operatorname{det} B=-\operatorname{det} A$.

4. Apabila pada suatu matriks terdapat 2 baris atau 2 kolom yang elemennya identik, maka nilai determinan matriks itu $=0$.

Contoh:

$$
\text { Jika } A=\left[\begin{array}{ccc}
2 & 1 & -1 \\
3 & 5 & 2 \\
2 & 1 & -1
\end{array}\right]
$$

Dengan elemen pada baris ke-1 dan ke-3 sama, maka:

$$
\operatorname{det} A=|A|=\left|\begin{array}{ccc}
2 & 1 & -1 \\
3 & 5 & 2 \\
2 & 1 & -1
\end{array}\right|
$$

$\operatorname{det} A=|A|=2 \cdot 5 \cdot(-1)+1 \cdot 2 \cdot 2+(-1) \cdot 3 \cdot 1-((-1) \cdot 5 \cdot 2$

$$
\begin{aligned}
& +2 \cdot 2 \cdot 1+1 \cdot 3 \cdot(-1)) \\
= & 0
\end{aligned}
$$

Jika $A=\left[\begin{array}{ccc}4 & 3 & 1 \\ 4 & 3 & 1 \\ 5 & 2 & -2\end{array}\right]$

Dengan elemen pada kolom ke-1 dan ke-2 sama, maka:

$$
\begin{aligned}
\operatorname{det} A=|A|= & 4.3 .(-2)+3 \cdot 1 \cdot 5+1.4 .2- \\
& (1.3 .5+4 \cdot 1 \cdot 2+3.4 .(-2)) \\
= & 0
\end{aligned}
$$

5. Apabila semua unsur sebarang baris atau kolom dikalikan dengan sebuah faktor selain 0 , maka nilai determinannya dikalikan dengan faktor itu.

\section{Contoh:}

$$
\begin{aligned}
\text { Jika } A= & {\left[\begin{array}{ccc}
2 & 3 & 1 \\
4 & -1 & 1 \\
5 & 2 & -3
\end{array}\right] } \\
\operatorname{det} A=|A|= & \left|\begin{array}{ccc}
2 & 3 & 1 \\
4 & -1 & 1 \\
5 & 2 & -3
\end{array}\right| \\
\operatorname{det} A=|A|= & 2 \cdot(-1) \cdot(-3)+3 \cdot 1 \cdot 5+1 \cdot 4 \cdot 2- \\
& (1 .(-1) \cdot 5 \cdot+2 \cdot 1 \cdot 2+3 \cdot 4 \cdot(-3)) \\
= & 66
\end{aligned}
$$

Jika elemen-elemen pada baris ke-1 dari matriks tersebut dikalikan 3, maka didapat matriks:

$$
B=\left[\begin{array}{ccc}
6 & 9 & 3 \\
4 & -1 & 1 \\
5 & 2 & -3
\end{array}\right]
$$

$$
\begin{aligned}
\operatorname{det} B=|B|= & \left|\begin{array}{ccc}
6 & 9 & 3 \\
4 & -1 & 1 \\
5 & 2 & -3
\end{array}\right| \\
\operatorname{det} B=|B|= & 6 .(-1) .(-3)+9.1 .5+3.4 .2- \\
& (3 .(-1) \cdot 5 .+6.1 .2+9.4 .(-3)) \\
= & 198
\end{aligned}
$$

Maka dari uraian diatas dapat dilihat:

$3 \operatorname{det} \mathrm{A}=\operatorname{det} \mathrm{B}$

$3.66=198$

6. Tanpa mengubah nilai determinan, semua elemen sebarang baris atau kolom dapat dikalikan dengan sebuah faktor selain 0 dan menambahkan atau mengurangi dari sebarang baris atau kolom yang lain.

Contoh:

Jika $A=\left[\begin{array}{ccc}1 & 2 & 3 \\ 2 & -1 & 3 \\ 1 & 0 & 1\end{array}\right]$ dan $B=\left[\begin{array}{ccc}5 & 0 & 9 \\ 2 & -1 & 3 \\ 1 & 0 & 1\end{array}\right]$

Maka nilai determinan masing-masing matriks tersebut adalah:

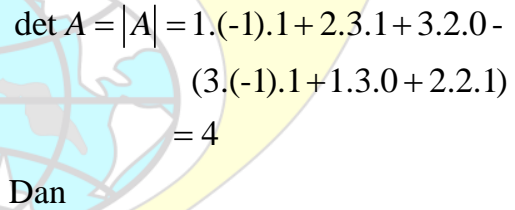

Dan

$\operatorname{det} B=|B|=5 .(-1) \cdot 1+0.3 \cdot 1+9 \cdot 2 \cdot 0$ -

$$
\begin{aligned}
& (9 \cdot(-1) \cdot 1+5 \cdot 3 \cdot 0+0 \cdot 2 \cdot 1) \\
= & 4
\end{aligned}
$$

7. Jika A dan B merupakan matriks-matriks persegi yang n maka, $\operatorname{det} A B=\operatorname{det} A \cdot \operatorname{det} B$

8. Jika suatu matriks merupakan matriks segitiga atas atau segitiga bawah, maka nilai determinannya merupakan hasil kali dari elemen-elemen yang tereletak pada diagonal utamanya.

Contoh:

Jika $A=\left[\begin{array}{ccc}4 & 0 & 0 \\ 3 & 5 & 0 \\ 5 & 1 & -3\end{array}\right]$ dan $B=\left[\begin{array}{ccc}2 & 1 & 5 \\ 0 & -1 & 1 \\ 0 & 0 & 2\end{array}\right]$ 
Maka nilai determinan masing-masing matriks tersebut adalah:

$$
\begin{aligned}
\operatorname{det} A=|A|= & 4.2 \cdot(-3)+0.0 .5+0.3 \cdot 1- \\
& (0.2 \cdot 5 .+4 \cdot 0.1+0.3 \cdot(-3)) \\
= & 24
\end{aligned}
$$

Dan

$$
\begin{aligned}
\operatorname{det} B=|B|= & 2 \cdot(-1) \cdot 2+1 \cdot 1 \cdot 0+5 \cdot 0 \cdot 0- \\
& (5 \cdot(-1) \cdot 0+2 \cdot 1 \cdot 0+1 \cdot 0 \cdot 2) \\
= & -4
\end{aligned}
$$

Langkah-langkah yang harus dilakukan dalam menentukan determinan suatu matriks dengan metode Chio adalah sebagai berikut:

Perhitungan determinan matriks dengan metode Chio dapat diterapkan pada semua matriks bujur sangkar asalkan elemen pada $a 11$ tidak sama dengan nol $\left(a_{11} \neq 0\right)$. Metode CHIO menghitung determinan matriks dengan cara mendekomposisi determinan yang akan dicari menjadi sub-sub determinan derajat dua $(2 \times 2)$ menggunakan elemen matriks baris ke-1 dan kolom ke-1 sebagai titik tolaknya. Dekomposisi tersebut dilakukan dengan menggunakan matriks berukuran $2 \times 2$ berikut:

$\left|\begin{array}{ll}a_{11} & a_{1 n} \\ a_{n 1} & a_{n n}\end{array}\right|$, for $n=1,2,3, \ldots$

Jika $A$ merupakan matriks persegi $A$ berukuran $n \times n$ :

$A=\left[\begin{array}{cccccc}a_{11} & a_{12} & \cdots & a_{1 i} & \cdots & a_{1 n} \\ a_{21} & a_{22} & \cdots & a_{2 i} & \cdots & a_{2 n} \\ \vdots & \vdots & \ddots & \vdots & \cdots & \vdots \\ a_{i 1} & a_{i 2} & \cdots & a_{i i} & \cdots & a_{i n} \\ \vdots & \vdots & \cdots & & \ddots & \vdots \\ a_{n 1} & a_{n 2} & \cdots & & \cdots & a_{n n}\end{array}\right]$

$\operatorname{det} A=|A|$

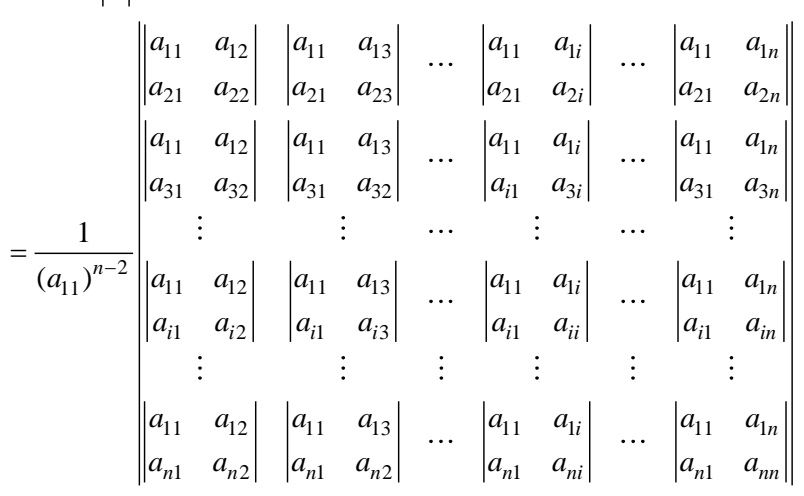$$
\operatorname{det} A=|A|=\frac{1}{(-21)^{1}}\left|\begin{array}{cc}
-21-(-16) & -63-(-58) \\
210-88 & 525-319
\end{array}\right|
$$$$
\operatorname{det} A=|A|=\frac{1}{(-21)^{1}}\left|\begin{array}{cc}
-5 & -5 \\
122 & 206
\end{array}\right|
$$$$
\operatorname{det} A=|A|=\frac{1}{(-21)}(-1030-(-610))
$$$$
\operatorname{det} A=|A|=\frac{-420}{-21}
$$$$
\operatorname{det} A=|A|=20
$$

$$
\operatorname{det} A=|A|=\frac{1}{\left(a_{11}\right)^{n-2}}\left|\begin{array}{cccc}
a_{11} & a_{12} & \cdots & a_{1, n-1} \\
a_{21} & a_{22} & \cdots & a_{2, n-1} \\
\vdots & \vdots & \ddots & \vdots \\
a_{n-1,1} & a_{n-1,2} & \cdots & a_{n-1, n-1}
\end{array}\right|
$$

Setiap dekomposisi determinan awal akan turun satu derajat, dekomposisi determinan dapat dihentikan sampai determinan tersebut menjadi berderajat dua.

$$
\operatorname{det} A=|A|=\frac{1}{\left(a_{11}\right)^{n-2}}\left|\begin{array}{cc}
a_{11} & a_{1, n-1} \\
a_{n-1,1} & a_{n-1, n-1}
\end{array}\right|
$$

\section{Contoh Soal:}

$A=\left[\begin{array}{cccc}1 & 3 & 2 & 5 \\ 6 & -3 & 4 & 1 \\ 0 & 2 & 1 & 3 \\ 6 & 7 & 2 & 5\end{array}\right]$

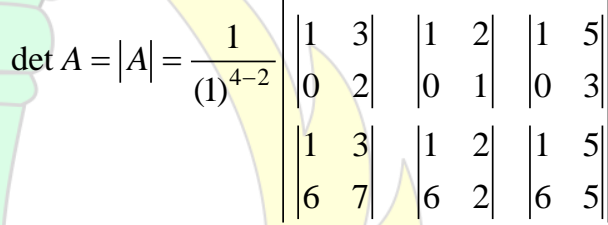

$$
\operatorname{det} A=|A|=\frac{1}{(1)^{2}}\left|\begin{array}{ccc}
-3-8 & 4-12 & 1-30 \\
2-0 & 1-0 & 3-0 \\
7-8 & 2-12 & 5-30
\end{array}\right|
$$

$$
\begin{aligned}
& \operatorname{det} A=|A|=\left|\begin{array}{ccc}
-21 & -8 & -29 \\
2 & 1 & 3 \\
-11 & -10 & -25
\end{array}\right| \\
& \operatorname{det} A=|A|=\frac{1}{(-21)^{1}}\left|\begin{array}{cc}
\left|\begin{array}{cc}
-21 & -8 \\
2 & 1
\end{array}\right| & \left|\begin{array}{cc}
-21 & -29 \\
2 & 3
\end{array}\right| \\
-21 & -8 \\
-11 & -10
\end{array}\right|\left|\begin{array}{ll}
-21 & -29 \\
-11 & -25
\end{array}\right|
\end{aligned}
$$




\section{PENUTUP}

\section{Simpulan}

Berdasarkan hasil studi literatur tentang cara menentukan determinan suatu matriks dengan metode Chio yang dilakukan penulis dapat ditarik kesimpulan sebagai berikut:

1. Konsep dasar determinan matriks.

2. Sifat-sifat yang berlaku dalam menentukan determinan matriks.

3. Penggunaan metode Chio pada penentuan determinan matriks yang berordo $n \times n$ dengan menyusutkan ordonya menjadi matriks yang berordo $(n-1) \times(n-1)$.

\section{Saran}

Berdasarkan pada proses penelitian yang dilakukan tentang cara menentukan determinan suatu matriks dengan metode Chio, maka saran-saran yang ingin disampaikan penulis adalah:

1. Pembahasan tentang determinan matriks dapat dikembangkan kembali misalkan dengan elemen-elemennya adalah bilangan kompleks.
2. Penelitian ini dapat dikembangkan pula dengan penyelesaian menggunakan program komputer, misalkan dengan software MATLAB, MathChad, dsb.

\section{DAFTAR PUSTAKA}

Anton, Howard. 2000. Dasar-dasar Aljabar Linier, Jilid I Edisi ketujuh. Batam: Interaksara.

Setiadji. 2008. Aljabar Linier. Yogyakarta: Graha Ilmu. Hari, Purwanto., Gina, Indriani., Erlina, Dayanti. 2005. Aljabar Linier. Jakarta: Ercontara Rajawali.

T.Sutojo., Bowo, N., Erna, Z.A., Setia, Astuti., Yuniarsih, Rahayu., Edy, Mulyanto. 2010. Aljabar Linier dan Matriks. Yogyakarta: Andi.

Imrona, Mahmud. 2013. Aljabar Linier Dasar, Edisi kedua. Jakarta: Erlangga.

Leon, Steven J. 2001. Aljabar Linier dan Aplikasinya, Edisi kelima. Jakarta: Erlangga.

Ruminta. 2009. Matriks Persamaan Linier dan Pemograman Linier. Bandung: Rekayasa Sains.

Anton, H., Pantur Silaban. 1987. Aljabar Linier Elementer, Edisi kelima. Jakarta: Erlangga.

Hadley, G. 1983. Aljabar Linier. Jakarta: Erlangga.

Anton, H. 2000. Dasar-Dasar Aljabar Linier, Jilid 1. Bandung: Interaksara. 